\title{
Estudo anatômico da porção intrapélvica do nervo isquiático em fetos de bovinos azebuados
}

Rosa Helena dos Santos FERRAZ

Gilmar Rodrigues LOPES ${ }^{1}$

Alan Peres Ferraz de MELO ${ }^{1}$

Irvênia Luiza de Santis

PRADA $^{2}$

\section{Correspondência para:}

ROSA HELENA DOS SANTOS FERRAZ

Rua Polônia, quadra 12, casa 07 - Jardim

Europa

78065-445-Cuiabá-MT

rhs.ferraz@terra.com.br

Recebido para publicação: 31/05/2004 Aprovado para publicação: 01/06/2005

\author{
1- Curso de Medicina Veterinária do Centro Universitário de Rio Preto - São \\ José do Rio Preto - SP \\ 2 - Faculdade de Medicina Veterinária e Zootecnia - Universidade de São \\ Paulo - USP
}

\section{Resumo}

O nervo isquiático é o maior de todos os nervos do organismo. Ele emerge da cavidade pélvica pelo forame isquiático maior como um cordão amplo, plano e acinzentado. Dirige-se caudal e ventralmente sobre a parte distal e lateral do ligamento largo da pelve. Há muitas evidências clínicas e experimentais de que a maior parte das injúrias que acometem o nervo isquiático, em bovinos, envolve a contribuição do $6^{\circ}$ nervo lombar para o referido nervo. Neste estudo foram analisados por meio de dissecção, a origem e sintopia do nervo isquiático, em 33 fetos de bovinos azebuados. O nervo isquiático mostra sua origem a partir dos ramos ventrais do $5^{\circ}$ e $6^{\circ}$ nervos lombares e do $1^{\circ}, 2^{\circ}$ e $3^{\circ}$ nervos sacrais. A origem mais freqüente para o nervo isquiático é representada pelo ramo ventral do $6^{\circ}$ nervo lombar e $1^{\circ}$ e $2^{\circ}$ nervos sacrais (100\%). Em 39,4\% desses casos, o nervo recebe contribuição do $5^{\circ}$ nervo lombar e, em 12,1\% dos casos, também do $3^{\circ}$ nervo sacral. A participação mais conspícua na formação do nervo isquiático é a do $6^{\circ}$ nervo lombar e $1^{\circ}$ nervo sacral $(39,4 \%)$, seguida somente do $1^{\circ}$ nervo sacral em $33,33 \%$ e da associação do $1^{\circ}$ e $2^{\circ}$ nervos sacrais em $18,18 \%$. O nervo isquiático revela íntima aposição na face ventral do sacro e em relação às raízes ventrais do $5^{\circ} \mathrm{e}$ $6^{\circ}$ nervos lombares. De modo geral, os resultados obtidos em relação à origem do nervo e sua sintopia, não mostram discordância com os correspondentes dados obtidos na literatura referente a bovinos de origem européia.

\section{Introdução}

O nervo isquiático pertence tanto ao plexo sacral (Ghoshal ${ }^{7}$ e Schaller et al. ${ }^{13}$ ) quanto ao lombossacro (Dyce et al. ${ }^{4}$ ) e, a despeito da terminologia, origina-se do tronco lombossacro (Seiferle ${ }^{16}$ ). Por meio de sua divisão em nervo tibial e fibular comum, é responsável pela inervação das estruturas da extremidade distal do membro pélvico. Ele emerge da cavidade pélvica pelo forame isquiático maior como um cordão amplo, plano e acinzentado que se dirige caudal e ventralmente sobre a parte distal (Vaughan ${ }^{17}$; Schwarze e Schröder ${ }^{15}$ ) e lateral do ligamento largo da pelve (Ghoshal').

Sendo o maior de todos os nervos do organismo (Schwarze e Schröder ${ }^{15}$; Seiferle ${ }^{16}$; Ellenberger e Baum ${ }^{5}$ ), é formado principalmente pelo último nervo lombar e o $1^{\circ}$ nervo sacral, recebendo também, uma contribuição ordinária do penúltimo nervo lombar e outra do $2^{\circ}$ nervo sacral (Schwarze e Schröder ${ }^{15}$; Ghoshal ${ }^{7}$; Dyce e Wensing ${ }^{3}$; Cox et al. ${ }^{2}$; Dyce et al. ${ }^{4}$ ). Vaughan ${ }^{17}$ aborda a origem do nervo isquiático de modo semelhante aos demais autores ressaltando a usual contribuição da raiz ventral do $5^{\circ}$ nervo lombar. Por outro lado, Schummer ${ }^{14}$ relata a origem desse nervo a partir das quatro primeiras raízes do plexo sacral, sem no entanto, especificá-las. Particularmente em relação a bovinos de origem indiana, Campos et al. ${ }^{1}$ relatam que em 19 vezes 
$(63,33 \%)$ o nervo isquiático originou-se das raízes ventrais do $6^{\circ}$ nervo lombar e do $1^{\circ} \mathrm{e}$ $2^{\circ}$ nervos sacrais; em 6 vezes também dos $3^{\circ}$ nervos sacrais $(20 \%)$; e em 5 vezes da raiz ventral do $5^{\circ}$ nervo lombar (16,67\%).

Segundo Lahunta ${ }^{9}$, há muitas evidências clínicas e experimentais de que a maior parte das injúrias que acometem o nervo isquiático, em bovinos, envolvem a contribuição do $6^{\circ}$ nervo lombar em sua formação. Após deixar o forame intervertebral, o $6^{\circ}$ nervo lombar corre ventralmente por um pronunciado sulco no sacro passando antes, lateralmente, para unirse aos dois primeiros nervos espinhais. $\mathrm{O} 6^{\circ}$ nervo espinhal lombar está propenso a compressão, nesse sulco ósseo (Cox et al. ${ }^{2}$ ) como ocorre na presença de sarcoma osteogênico da porção ventral do referido osso. Ao longo de seu trajeto, pode sofrer lesões por ocasião de injeções intramusculares inadequadamente realizadas, levando a graus variáveis de paralisia, reversíveis ou não (Lahunta9). Já em 1986, Lahunta e Habel ${ }^{10}$ reafirmam como possíveis causas de injúrias ao nervo isquiático, fraturas de $7^{a}$ vértebra lombar, luxação sacro-ilíaca, fratura de sacro, fratura do corpo do ílio na altura da incisura isquiática maior, injeções glúteas mal direcionadas, pinos intramedulares proximais no fêmur mal direcionados, fratura do fêmur e injeções mal direcionadas na face caudal na coxa. Além do aspecto relatado por Lahunta ${ }^{9}$, o parto distócico, seja pelo tamanho do feto ou seu inadequado posicionamento, é descrito por Dyce et al. ${ }^{3}$ como outra causa de injúria ao nervo isquiático.

Por outro lado, a grande maioria das informações relativas ao comportamento do nervo isquiático, em bovinos, é obtida nos Tratados de Anatomia Veterinária que, de modo geral referem-se a animais de origem européia. Entretanto, em nosso país, a difusão dos bovinos de origem indiana é abrangente e desse modo, devemos considerar a possibilidade de diferenças anatômicas entre os dois grupos.

Assim sendo, objetivamos neste trabalho analisar as origens do nervo isquiático em bovinos azebuados e verificar sua sintopia em relação à cavidade pélvica.

\section{Materiais e Métodos}

Para o desenvolvimento desta pesquisa, foram coletados 33 fetos de bovinos azebuados em matadouros industriais da região de São José do Rio Preto, sendo 21 machos e 12 fêmeas. Após a identificação os animais foram perfundidos por uma das artérias umbilicais com solução aquosa de formaldeído a 10\%. Concluído o processo de conservação, eles foram reduzidos e eviscerados. Para a dissecção, utilizaram-se instrumentos cirúrgicos de rotina e alguns instrumentos cirúrgicos para oftalmologia. As peças reduzidas foram colocadas em decúbito dorsal, iniciando-se a dissecção por uma incisão na linha mediana ventral da região púbica até a perineal. Após o rebatimento da parede abdominal ventral e músculos mediais da coxa incisou-se a sínfise pelvina para a evidenciação da origem do nervo isquiático, via cavidade pélvica. $\mathrm{Na}$ seqüência, retiraram-se os vasos da região lombossacral e aqueles que emergiam pelo forame isquiático maior. Os vários ramos ventrais dos nervos espinham que formavam o nervo isquiático foram visualizados e parte do ligamento sacrotuberal largo foi rebatido para melhor identificação o tronco do nervo. Algumas peças foram fotografadas para a documentação dos resultados.

\section{Resultados}

O nervo isquiático mostrou a sua origem a partir do ramo ventral do $6^{\circ}$ nervo lombar e do $1^{\circ}$ e $2^{\circ}$ nervos sacrais em todos os 33 casos estudados (fig. 01 - obs. 01). Em 13 desses casos (39,4\% - Obs. 3, 5, 6, $10,15,18,20,24,26,28,31,32$, e 33 - fig. 02 - obs. 15), além das raízes citadas, o nervo isquiático recebeu contribuição do ramo ventral do $5^{\circ}$ nervo lombar. E em 4 outros casos $(12,1 \%$ - Obs. 11, 21, 25 e 27 - fig. 03 - obs. 11) a origem do nervo isquiático recebeu contribuição do $3^{\circ}$ nervo sacral. 


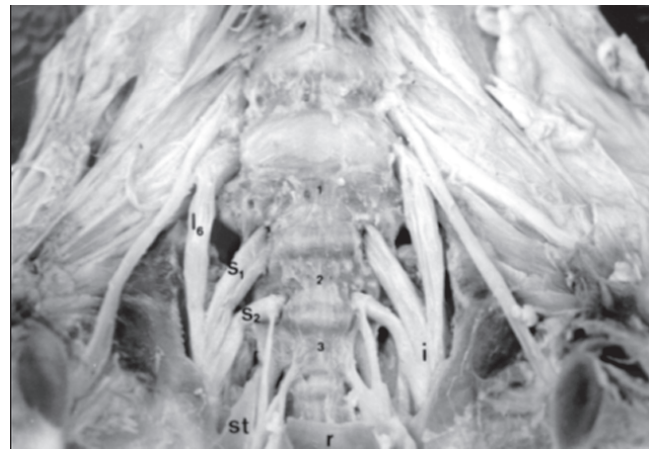

Figura 1 - Cavidade pélvica de feto bovino: vista ventral do osso sacro evidenciando as raízes ventrais do $6^{\circ}$ nervo lombar $\left(\mathbf{I}_{6}\right) \mathrm{e}$ $1^{\circ}\left(\mathbf{S}_{1}\right)$ e $2^{\circ}\left(\mathbf{S}_{2}\right)$ nervos sacrais confluindo para a formação do nervo isquiático (i) que emerge da cavidade pélvica pelo forame isquiático maior. st: ligamento sacrotuberal largo, r: reto, 1, 2 e 3: primeira, segunda e terceira vértebras sacrais, respectivamente. Notar a contribuição equilibrada entre os ramos ventrais do $6^{\circ}$ nervo lombar $1^{\circ}$ nervo sacral

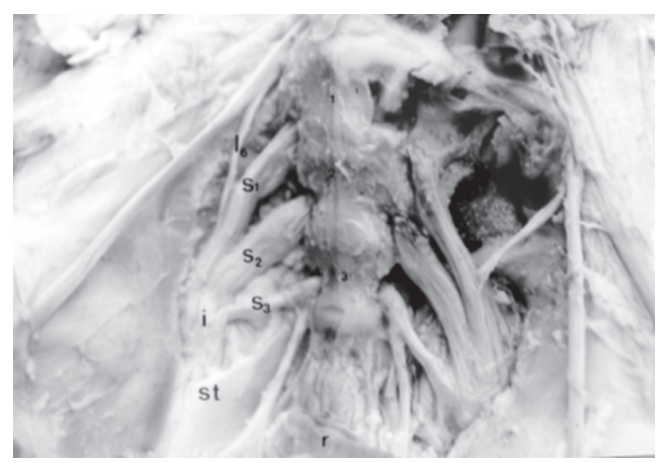

Figura 3- Cavidade pélvica de feto bovino: vista ventral do osso sacro mostrando as raízes ventrais do $6^{\circ}$ nervo lombar $\left(\mathbf{I}_{6}\right)$ e $1^{\circ}$ $\left(\mathbf{S}_{1}\right), 2^{\circ}\left(\mathbf{S}_{2}\right)$ e $3^{\circ}\left(\mathbf{S}_{3}\right)$ nervos sacrais na formação do nervo isquiático (i). st: ligamento sacrotuberal largo, r: reto, 1, $2 \mathrm{e}$ 3: primeira, segunda e terceira vértebras sacrais, respectivamente. Neste caso os ramos ventrais do $1^{\circ} \mathrm{e} 2^{\circ}$ nervos sacrais contribuem na mesma proporção para a formação do nervo. No antímero esquerdo nota-se desarticulação proposital entre o osso sacro e o íleo para a evidenciação do ponto de fragilidade da raiz ventral do $6^{\circ}$ nervo lombar

Não foi observada assimetria, ou seja, a formação do nervo isquiático ocorreu, no mesmo indivíduo, de forma semelhante no antímero direito e esquerdo.

A dissecção das peças anatômicas além de permitir identificar as várias contribuições à formação do nervo isquiático também possibilitou a verificação de proporções diferenciadas entre elas. Sendo assim, na formação do nervo isquiático, os ramos ventrais do $6^{\circ}$ nervo lombar e $1^{\circ}$

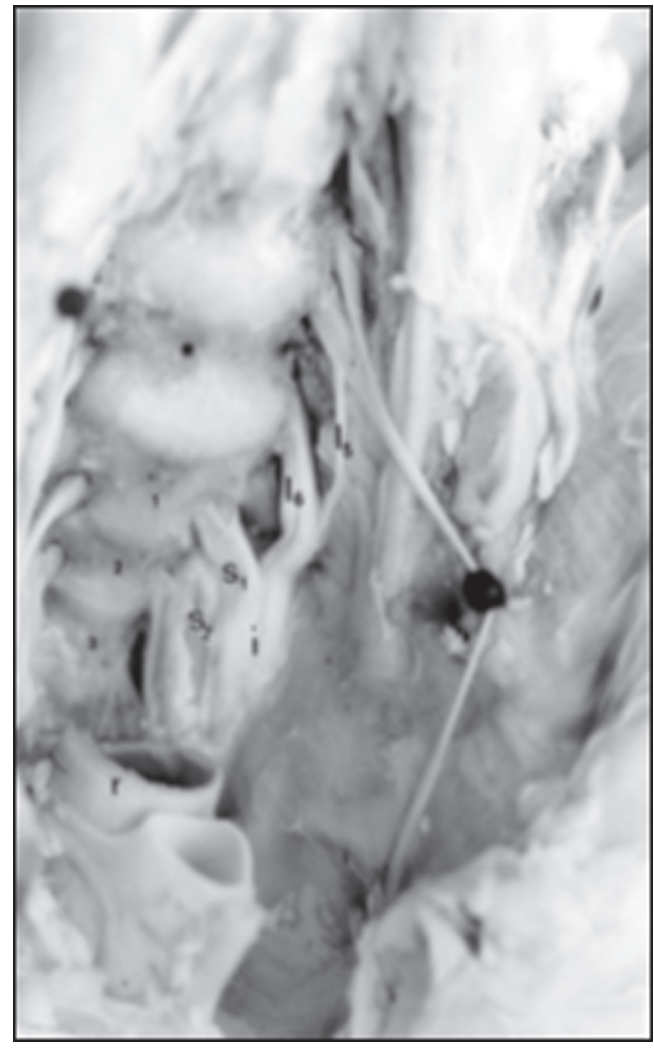

Figura 2- Cavidade pélvica de feto bovino: vista ventro-lateral esquerda do osso sacro evidenciando as raízes ventrais do $5^{\circ}\left(\mathbf{I}_{5}\right)$ e $6^{\circ}$ (I) nervos lombares e $1^{\circ}\left(\mathbf{S}_{\mathbf{t}}\right)$ e $2^{\circ}\left(\mathbf{S}_{2}\right)$ nervos sacrais confluindo para a formação do nervo isquiático (i). r: reto, 1, 2 e 3: primeira, segunda e terceira vértebras sacrais, respectivamente. Observar que a contribuição dada pelo $2^{\circ}$ nervo sacral é menor que a do $5^{\circ}$ nervo lombar

nervo sacral foram os mais conspícuos e contribuíram igualmente para a formação do nervo isquiático em 13 casos $(39,4 \%$ Obs. 1, 6, 10, 14, 15, 18, 22, 23, 24, 26, 28, 32 e 33; fig. 01); já o ramo ventral do $1^{\circ}$ nervo sacral foi o componente mais conspícuo em 11 casos (33,33\% - Obs. 2, 3 , $4,5,7,8,9,16,20,30$ e 31); em 6 casos (18,18\% - Obs. $11,13,19,21,27$ e 29; fig. 03) os ramos ventrais do $1^{\circ}$ e $2^{\circ}$ nervos sacrais contribuíram igualmente. Em outros 2 casos (6,06\% - Obs. 12 e 17) houve uma contribuição conspícua dos ramos ventrais do $6^{\circ}$ nervo lombar e $1^{\circ}$ e $2^{\circ}$ nervos sacrais. A maior contribuição por parte do $2^{\circ}$ nervo sacral ocorreu em um único caso $(3,03 \%$ Obs. 25). Com relação a menor contribuição 
à formação do nervo isquiático, ela ocorreu em 7 casos envolvendo o ramo ventral do $5^{\circ}$ nervo lombar ( $\mathrm{n}=13 ; 53,84 \%$ - Obs. 3 , $6,20,24,26,31,32)$, em 6 casos o $2^{\circ}$ nervo sacral $(\mathrm{n}=33 ; 18,18 \%$ - Obs. $5,10,15,16$, 18 e 28; fig. 02); em 3 casos ( $n=4 ; 75 \%$ Obs. 11, 25 e 27$)$ o $3^{\circ}$ nervo sacral; em 2 casos (n $=33 ; 6,06 \%$ - Obs. 11 e 25$)$ o ramo ventral do $6^{\circ}$ nervo lombar.

A sintopia do segmento estudado do nervo isquiático, em relação à cavidade pélvica, foi descrita a partir das raízes ventrais do $5^{\circ}$ e $6^{\circ}$ nervos lombares e dos $1^{\circ}, 2^{\circ}$ e $3^{\circ}$ nervos sacrais por serem estas as contribuições encontradas para a sua formação. Cada uma das raízes citadas emergiu pelo respectivo forame intervertebral ventral direcionando-se caudalmente e unindo-se para formar o tronco de nervo isquiático. Este tronco formou-se na altura do forame isquiático maior, por onde emergiu, deixando a cavidade pélvica. Desde a saída pelo forame até a formação do tronco, as raízes ventrais do $1^{\circ}, 2^{\circ}$ e $3^{\circ}$ nervos sacrais descreveram seu trajeto junto ao teto da cavidade pélvica, enquanto que as raízes do $5^{\circ}$ e $6^{\circ}$ nervos lombares adentraram a cavidade passando ventralmente a asa do sacro, estando a raiz do $6^{\circ}$ nervo lombar em contato direto (fig. 3) com a superfície óssea e, a do $5^{\circ}$ nervo lombar, em posição ventro - lateral a ela.

\section{Discussão}

Adotamos neste trabalho os termos anatômicos listados no International Committee on Veterinary Gross Anatomical Nomenclature $^{8}$, que indica o nervo isquiático como sendo pertencente ao plexo sacral, de maneira semelhante ao afirmado por Ghoshal $^{7}$ e Schaller et al. ${ }^{13}$. No entanto, origina-se do tronco lombossacral (Seiferle ${ }^{16}$ ) que pertence ao referido plexo, e é assim denominado por conter ramos do plexo lombar reforçando o plexo sacral (Schaller et al. $\left.{ }^{13}\right)$. Acreditamos que a denominação de plexo lombossacro, encontrada no texto de Dyce et $a .^{4}$, seja uma forma genérica de abordar todos os nervos que se originam dos plexos lombar e sacral e que possuem importância clínico-cirúrgica, conforme enunciado no prefácio da obra: “...visa enfatizar aquelas características e tópicos que possuem relevância direta na prática clínica...", sendo portanto, uma obra de cunho mais prático e não exclusivamente anatômica. O comportamento do curto segmento do nervo isquiático no interior $\mathrm{da}$ cavidade pélvica, observado no presente trabalho, vem ao encontro das informações exaradas por Vaughan ${ }^{17}$; Schwarze e Schröder ${ }^{15}$ e Ghoshal ${ }^{7}$.

As informações de interesse, sobre o nervo isquiático obtidas nos tratados (Schwarze e Schröder ${ }^{15}$, Dyce e Wensing ${ }^{3}$, Seiferle ${ }^{16}$, Ghoshal ${ }^{7,}$ Lahunta $^{9}$, Schummer ${ }^{14}$, Ellenberger e Baum ${ }^{5}$, Lahunta e Habel ${ }^{10}$, Dyce et $\mathrm{al}^{4}{ }^{4}$ ), provavelmente referem-se a animais de origem européia, diferentemente deste estudo, que enfocou animais azebuados, conforme também relatado por Campos et al. ${ }^{1}$. De modo semelhante, Vaughan ${ }^{17}$ não especifica a raça dos animais utilizados, mas animais de origem européia podem ser observados em suas ilustrações. Cox et al. ${ }^{2}$ utilizaram animais da raça Hereford como objeto de estudo.

Com relação à faixa etária, todos os tratadistas referem-se a animais adultos, semelhante ao aludido por Vaughan ${ }^{17}$ que trabalhou também com animais jovens, enquanto Cox et al. ${ }^{2}$ utilizaram principalmente animais adultos. A utilização de fetos neste estudo e também por Campos et al. ${ }^{1}$ deve-se à maior facilidade de obtenção do material, bem como de seu manejo, em relação a animais adultos. Ainda, encontrase fundamentada na "hipótese de Fürbringer "(") referida em Locchi ${ }^{11}$, segundo a qual toda massa muscular embrionária recebe, sempre e exclusivamente, sua inervação do correspondente neurômero, inervação que se conserva mesmo após eventuais migrações e divisões (onto ou filogênicas) do esboço muscular, ou seja, "a relação neurótomo-miótomo, uma vez estabelecida, torna-se definitiva". Sendo 
assim, aventamos a possibilidade de que os resultados obtidos possam sinalizar o padrão de formação do nervo isquiático em bovinos azebuados, seja qual for a faixa etária considerada. Desse modo, com base nos resultados por nós obtidos bem como nos da literatura consultada, acreditamos ser muito provável que o nervo isquiático apresente, no adulto, origem e sintopia semelhante ao que encontramos no feto, guardando-se as devidas proporções entre as estruturas do sistema nervoso e os tecidos adjacentes.

Em bovinos azebuados, o nervo isquiático é formado pelas raízes ventrais do $5^{\circ}$ e $6^{\circ}$ nervos lombares e $1^{\circ}, 2^{\circ}$ e $3^{\circ}$ nervos sacrais. Schwarze e Schröder ${ }^{15}$; Seiferle ${ }^{16}$ e Ellenberger e Baum ${ }^{5}$ descrevem que a principal contribuição à formação do nervo isquiático é representada pelo último nervo lombar e $1^{\circ}$ nervo sacral corroborando nossos resultados, nos quais $39,4 \%$ das observações correspondiam a esses ramos. No entanto, em 33,33\% dos casos, a maior contribuição era dada pelo $1^{\circ}$ nervo sacral e em $18,18 \%$ pelos $1^{\circ}$ e $2^{\circ}$ nervos sacrais, na mesma proporção. Sendo assim, fica claro que as contribuições mais conspícuas para a formação do nervo isquiático foram dadas pelas raízes ventrais do $6^{\circ}$ nervo lombar e $1^{\circ}$ e $2^{\circ}$ nervos sacrais. Em menor porcentagem, contribuições conspícuas e equiparadas entre os ramos ventrais do $6^{\circ}$ nervo sacral e $1^{\circ}$ e $2^{\circ}$ nervos sacrais ocorreram em 6,06\% dos casos. Contribuição conspícua exclusiva do $2^{\circ}$ nervo sacral $(3,03 \%)$, observada neste estudo, não foi citada pelos autores consultados. Especificamente em relação a animais de origem indiana, em nossos resultados, a participação das raízes ventrais do $5^{\circ}$ nervo lombar $(39,4 \%)$ e $3^{\circ}$ nervo sacral $(12,1 \%)$ na formação do nervo isquiático, respectivamente, diferiram dos de Campos et al. ${ }^{1}(16,67 \%$ e $20 \%)$, embora concordemos que o arranjo mais freqüentemente encontrado na formação do nervo isquiático seja constituído pelas raízes ventrais do $6^{\circ}$ nervo lombar e $1^{\circ}$ e $2^{\circ}$ nervos sacrais.

Em relação a menor contribuição à formação do nervo isquiático, Schwarze e Schröder ${ }^{15}$; Seiferle ${ }^{16}$; Ellenberger e Baum ${ }^{5}$ referem uma contribuição ordinária do penúltimo nervo lombar. No entanto, neste estudo essa contribuição atingiu $39,4 \%$, o que nos faz concordar com Vaughan ${ }^{17}$, considerando-a, portanto, como uma contribuição usual. Por outro lado, Schwarze e Schröder ${ }^{15}$; Ghoshal ${ }^{7}$; Dyce e Wensing; Cox et al. ${ }^{2}$; Dyce et al. ${ }^{4}$ também relatam contribuição rara para o $2^{\circ}$ nervo sacral, o que concordamos, pois esta atingiu apenas $12,1 \%$.

$\mathrm{Na}$ origem do nervo isquiático em animais azebuados a sintopia entre as raízes nervosas do $5^{\circ}$ e $6^{\circ}$ nervos lombares e a face ventral da asa do sacro revelam a susceptibilidade dessa estrutura, conforme o relatado por Cox et al. ${ }^{2}$; Lahunta ${ }^{9}$, Lahunta e Habel ${ }^{10}$ e Dyce et al. ${ }^{3}$.

Os dois antímeros mostraram similitude de origem e sintopia do nervo isquiático. Entretanto, exibindo ou não simetria bilateral, é certo que o nervo isquiático sempre se mostrou constituído por dois ou mais nervos espinhais, o que confirma sua característica de nervo plurissegmentar (Machado $^{12}$ ).

De tudo que foi exposto, ficamos com a impressão de que não há diferenças marcantes no comportamento do nervo isquiático entre animais de origem européia (dados trazidos pela literatura consultada) e animais azebuados (dados obtidos em nossos resultados), sendo essa informação importante como subsídio para abordagens clínicas ou cirúrgicas que envolvam as estruturas estudadas.

\section{Conclusão}

1 - O nervo isquiático mostrou sua origem a partir dos ramos ventrais do $5^{\circ} \mathrm{e}$ $6^{\circ}$ nervos lombares e do $1^{\circ}, 2^{\circ}$ e $3^{\circ}$ nervos sacrais.

2 - Como origem constante (100\%) do nervo isquiático foi assinalada a 
participação do ramo ventral do $6^{\circ}$ nervo lombar e do $1^{\circ}$ e $2^{\circ}$ nervos sacrais. Registrouse ainda contribuição do $5^{\circ}$ nervo lombar $(39,4 \%)$ e também do $3^{\circ}$ nervo sacral $(12,1$ $\%)$.

3 - A participação mais conspícua na formação do nervo isquiático foi representada pelo $6^{\circ}$ nervo lombar e $1^{\circ}$ nervo sacral $(39,4 \%)$, seguida somente pelo $1^{\circ}$ nervo sacral $(33,33 \%)$, pela associação do $1^{\circ}$ e $2^{\circ}$ nervos sacrais $(18,18 \%)$ e pelas raízes ventrais do $6^{\circ}$ nervo lombar, $1^{\circ}$ e $2^{\circ}$ nervos sacrais $(6,06 \%)$.

4 - Em sua origem, o nervo isquiático revelou íntima aposição na face ventral do sacro e as raízes ventrais do $5^{\circ}$ e $6^{\circ}$ nervos lombares.

5 - Os resultados obtidos em relação à origem do nervo isquiático, em fetos de bovinos azebuados, de modo geral, não mostraram discordância com os correspondentes dados obtidos na literatura consultada alusiva a bovinos de origem européia.

\section{Anatomical study of the intrapelvic portion of ischiatic nerve in fetuses in crossbred zebu cattle}

\section{Abstract}

The sciatic nerve is the largest of all nerves of the body. It emerges from the pelvic cavity through the major sciatic foramen as a wide, flat and brownish cord. It extends caudally and ventrally over the distal and lateral part of the pelvic broad ligament. There are several experimental and clinical evidences supporting that the majority of injuries affecting the sciatic nerve in bovines are associated with its $6^{\text {th }}$ lumbar nerve. This study analyzed the sciatic nerve origin and topography by means of dissection in 33 crossbred zebu fetuses. The sciatic nerve originates from the ventral branches of the $5^{\text {th }}$ and $6^{\text {th }}$ lumbar nerves and $1^{\text {st }}, 2^{\text {nd }}$ and $3^{\text {rd }}$ sacral nerves. The most frequent origin of the sciatic nerve is represented by the ventral branch of the $6^{\text {th }}$ lumbar nerve and $1^{\text {st }}$ and $2^{\text {nd }}$ sacral nerves $(100 \%)$. The most conspicuous participation in the sciatic nerve formation is from the $6^{\text {th }}$ lumbar nerve and $1^{\text {st }}$ sacral nerve $(39.4 \%)$, followed only by the $1^{\text {st }}$ sacral nerve in $33 \%$ and from the association of the $1^{\text {st }}$ and $2^{\text {nd }}$ sacral nerves in $18.18 \%$. The sciatic nerve shows close apposition in the sacral ventral face and as to the $5^{\text {th }}$ and $6^{\text {th }}$ lumbar nerve ventral roots. In general, the obtained results concerning the nerve origin and its topography do not demonstrate any discrepancy when compared to data from the literature regarding European cattle.

\section{Referências}

1 CAMPOS, D.B.; SILVA, F.O.C.; SEVERINO, R.S.; DRUMMOND, S.S.; LIMA, E.M.M. Origens e distribuições dos nervos isquiáticos em fetos de bovinos azebuados. IN: CONGRESSO BRASILEIRO DE MEDICINA VETERINÁRIA, 28, Salvador, 2001. Livro de resumos. Sociedade Brasileira de Medicina Veterinária e Sociedade de Medicina Veterinária da Bahia, 2001. p. 38

2 COX, V.S.; BREAZILE, J.E.; HOOVER, T.R. Surgical and anatomical study of calving paralysis. American Journal of Veterinary Research, v. 36, n. 4, part 1, p. 427-430, 1975.
Key-words: Sciatic nerve. Anatomy. Bovine.
3 DYCE, K.M.; WENSING, C.J.G. Essentials of bovine anatomy. Philadelphia: Lea \& Febiger, 1971. p. 111.

4 DYCE, K.M.; SACK, W.O.; WENSING, C.J.G. Tratado de anatomia veterinária. Rio de Janeiro: Guanabara Koogan, 1990. p. 220, 501-2.

5 ELLENBERGER, W.; BAUM, H. Handbuch der vergleichenden anatomie der haustiere. 18. ed. Berlin: Springer, 1985. p. 917.

6 FÜRBRINGER, apud LOCCHI 1932.

7 GHOSHAL, N.G. Nervos espinhais. In: GETTY, R. SISSON/GROSSMAN Anatomia dos animais domésticos. 5. ed. Rio de Janeiro: Interamericana, 1981. v. 1, p. 1068-9. 
8 INTERNATIONAL COMMITTEE ON VETERINARY GROSS ANATOMICAL NOMENCLATURE. Nomina Anatomica Veterinaria. 4. ed. Zurich, 1994. (Together with nomina histologica, 2. ed., 1992 and nomina embriologica veterinaria 1992).

9 LAHUNTA, A. Veterinary neuroanatomy and clinical neurology. 2. ed. Philadelphia: W.B. Saunders Company, 1983. p. 71-2.

10 LAHUNTA, A.; HABEL, R.E. Applied veterinary anatomy. Philadelphia: W.B. Saunders Company, 1986. p. 142.

11 LOCCHI, R. Verificação experimental da inervação motora da porção cervical do musculus platysma no Tamanduá tetradactyla. Revista de Biologia e Hygiene, v. 3 , p. $26-7,1932$

12 MACHADO, A.B.M. Neuroanatomia funcional. 2. ed. São Paulo: Atheneu, 1993. p. 101.

13 SCHALLER, O.; CONSTANTINESCU, G.M.; HABEL, R.E.; SACK, W.O.; SIMOENS, P.; DE VOS, N.R. Illustrated veterinary anatomical nomenclature. Stuttgart: Ferdinand Enke Verlag, 1992. p. 494.

14 SCHUMMER, A. Anatomia degli uccelli domestici. Milano: Casa Editrici Ambrosiana, 1984. p. 146.

15 SCHWARZE, E.; SCHRÖDER, L. Sistema nervioso Órganos de los sentidos. Zaragoza: Acribia, 1970. p. 82-3 (Compendio de anatomia veterinária, v. 4).

16 SEIFERLE, E. Nervensystem sinnesorgane endokrine drüsen. Berlim: Paul Parey, 1975. p. 240. (Lehrbuch der anatomie der hustiere, v. 4).

17 VAUGHAN, L.C. Peripheral nerves injuries: an experimental study in cattle. The Veterinary Record, v. 76, n.46, p. 1293-1301, 1964. 